\title{
COMUNICACIÓN
}

\section{Breve descripción de Taxorchis schistocotyle Beddard, 1914 (Trematoda, Cladorchiidae) por microscopia electrónica de barrido}

\author{
LEONOR GAUNA AÑASCO*, y FÉLIX A. MARTÍNEZ**
}

\section{SHORT DESCRIPTION OF Taxorchis schistocotyle BEDDARD, 1914 (TREMATODA, CLADORCHIIDAE) WITH SCANNING ELECTRON MICROSCOPE}

The study describes some morphological trait of Taxorchis schistocotyle Beddard, 1914 (Trematoda, Cladorcniidae) using scanning electron microscope (SEM). Specimens were removed from small instestine during necropsy of Hydrochoeris hydrochaeris (Rodentia, Hydrocheoridae). Samples were fixed in glutaraldehid 3\% in sodium monoacid phosphate buffer with dehidratation in acetones of increasing graduation. Diagnosis technique used was useful to survey and differentiation among species that parasite Argentinean wild mammalians.

Key words: Taxorchis schistocotyle, trematoda, scanning electron microscope, morphology, Hydrochoeris hydrochaeris.

\section{INTRODUCCIÓN}

El Hydrochoeris hydrochaeris (carpincho o capibara) se encuentra ampliamente distribuida desde Panamá, donde se registra una especie endémica Hydrochaeris isthmius, hacia el sur, fundamentalmente en las cuencas del Orinoco y Amazonas.

Las mayores densidades se dan en aquellos hábitats con buena disponibilidad de agua, ya que necesitan de este elemento para importantes funciones fisiológicas, como la termorregulación y copula ${ }^{13}$. Es un herbívoro selectivo que se alimenta principalmente de gramíneas bajas y ciperáceas, tal como se han observado en algunas provincias del nordeste argentino. Las hembras son muy prolíficas con camadas que se componen en promedio de cuatro, las que nacen muy desarrolladas, alcanzando la madurez sexual aproximadamente al año y medio de vida.

Su explotación mediante un sistema intensivo, es una actividad económica y logísticamente viable; presenta beneficios productivos y gran utilidad ecológica ${ }^{1,5}$. Es interesante consignar que se han desarrollado y evaluado sistemas de producción en Brasil, Colombia, Venezuela y mas recientemente en Argentina, a través de la Estación Experimental Delta del Paraná (INTADelta).

Merecen destacarse los estudios realizados sobre la biología básica y manejo experimental que sirvieron de fundamento para la política actual $^{11,12,16}$, de preferencias alimentarías, identificando las plantas consumidas ${ }^{6}$, de

\footnotetext{
* Cátedra de Histología y Embriología, Facultad de Ciencias Veterinarias. (UBA) Av. Chorroarin 280 (1427) Buenos Aires, Argentina.

** Cátedra de Zoología y Ecología, Facultad de Ciencias Veterinarias (UNNE) Sargento Cabral 2100 (3400) Corrientes, Argentina.
} 
dinámica poblacional y productiva de la especie ${ }^{14}$, de fisiología reproductiva en cautiverio abarcando la anatomía funcional del aparato reproductor de la hembra².

Las enfermedades juegan un papel importante en el éxito / fracaso de dichos esquemas, por lo que su conocimiento es un punto muy trascendental en cualquier proyecto de conservación $^{3,10,15}$.

Se han detectado diversas enfermedades en poblaciones naturales que pueden desarrollarse en cautiverio, como, brucelosis y leptopirosis ${ }^{4}$; tripanosomiasis ${ }^{21}$ y endoparasitosis ${ }^{7,9,17,20}$ de gran importancia, por constituir una fuente de alimento en este momento que las economías regionales necesitan incorporar actividades productivas no tradicionales, compatibles con la realidad geográfica y ecológica de cada región.

Los helmintos son especialmente problemáticos en animales cautivos, en altas densidades, y bajo
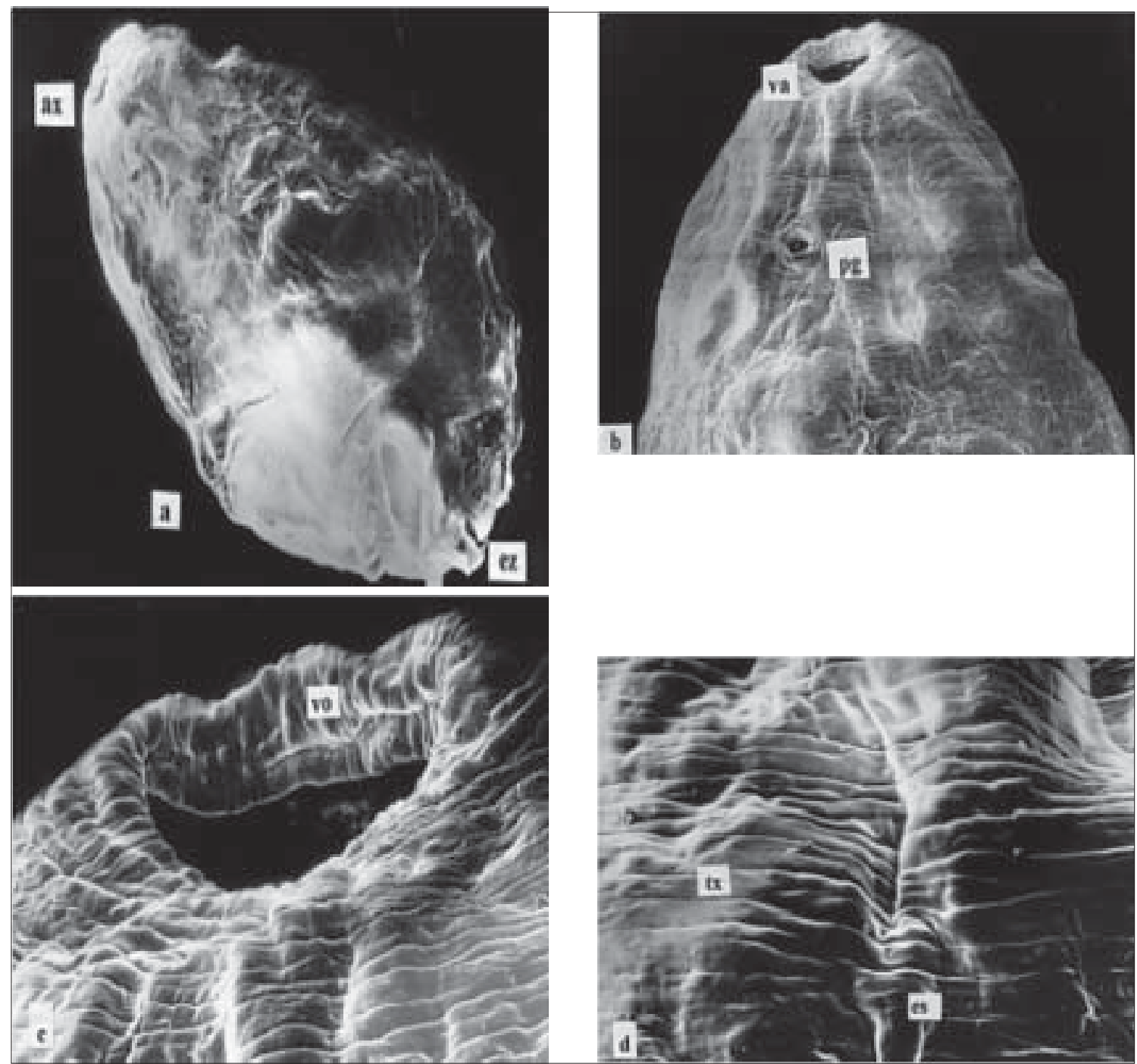

Figura 1. Taxorchis schistocotyle. a, Vista general (X20): extremo anterior (ax); extremidad posterior (ez); b, Región anterior, referencia de la ventosa oral (va) y el poro genital ventral (pg) (X40); c, Extremidad anterior mostrando detalles de la ventosa oral (va)., muscular, bien desarrollada (X180); d, Fragmento del tegumento donde se observa los plegamientos longitudinales y transversales mas o menos marcados (tx) y espinas (es) poco abundantes que actúan como mecanismo de fijación. 
un medio ambiente y dieta diferente de los naturales, lo que incrementa su susceptibilidad a contraerlos ${ }^{15}$.

El objetivo del presente trabajo es dar a conocer determinados aspectos de la morfología de Taxorchis schistocotyle empleando microscopía externa de barrido (MEB).

\section{MATERIAL Y MÉTODOS}

El material fue obtenido de 10 ejemplares de $H$. hydrochaer, de diferentes edades y sexo, remitidos por los zoológicos provinciales y privados, como así también de productores de la zona al Servicio de Identificación de Animales Silvestres, anexo a la Cátedra de Zoología y Ecología de la Facultad de ciencias Veterinarias de la Universidad Nacional del Nordeste.

La recuperación de los parásitos adultos e inmaduros del tracto gastrointestinal se realizo de acuerdo a las técnicas de necropsias tradicionales.

Para su clasificación fueron observados bajo lupa estereoscópica y al microscopio óptico, clarificándolos con ácido acético al 10\% durante 24 horas y posteriormente en glicerina pura hasta lograr el punto deseado ${ }^{8}$.

En la observación al microscopio electrónico de barrido se siguieron los siguientes pasos: 1 . Fijación con glutaraldehido (GAL) al 3\% en buffer fosfato monoácido de sodio; 2 . Deshidratación en acetonas de gradación creciente; 3. Punto critico con $\mathrm{CO}_{2}$ líquido y metalizado con oro paladio ${ }^{18,19}$.

\section{RESULTADOS}

Los ejemplares recolectados se hallaban insertos firmemente en la mucosa del intestino grueso. Cuerpo de forma piriforme, rojo cuando fresco y una longitud de $14 \mathrm{~mm}$ de largo por 6 $\mathrm{mm}$ de ancho. Ventosa oral provisto de divertículo. Esófago manifiesto, ciegos colocados lateralmente, pocos ramificados, extendiéndose hacia el extremo posterior del organismo. Poro genital, con ventosa genital, ampliamente separados del ovario. Acetabulum terminal. Poro excretor ubicado en la región posterior.

En la Figura 1 se ofrecen algunos aspectos de Taxorchis schistocotyle por medio de MEB, que permiten una mejor interpretación de su estructura externa.

\section{DISCUSIÓN Y CONCLUSIONES}

Taxorchis schistocotyle fue registrado por Travassos et al (1969) en el Brasil y Lombardero y col (1973), para la Argentina. Nuestras observaciones concuerdan en líneas generales con los citados autores.

Se reporta la primera descripción por microscopía electrónica de barrido en la Argentina.

Se concluye que la técnica de diagnóstico utilizada son de gran valor para el reconocimiento y diferenciación de otras especies, mediante la comparación de sus características morfológicas.

\section{REFERENCIAS}

1.- ALHO C J R, CAMPOS Z M S, GONCALVES H C. Ecología da capibara (Hydrochaeris hydrochaeris, rodentia) do Pantanal: I. Hábitats, densidades e tamanho de grupo. Revista Brasileira de Biología 1987; 47: 8797.

2.- AZCARATE T. Sociobióloga y manejo del capibara (Hydrochoeris hydrochaeris). Doñana, Acta Vertebrado 1980; 7: 1-228.

3.- BALLOU J D. Assessing the risk of infectious diseases in captive breeding and reintroduction programs. J Zoo and Wildl Med 1993; 24: 327-35.

4.- BELLO N A. Brucelosis en chiguires (Hydrochoeris hydrochaerus) del Estado Apure. Segundo Seminario sobre chigüires y Babas. Programas y Resúmenes. 1976. pp. 2 Maracay, Venezuela.

5.- FUERBRINGER J. El chigüiro, su cría y explotación racional. Orientación Agropecuaria 1974; 19: 5-59.

6.- GONZÁLEZ E. Digestive physiology and feeding of Capibara (Hydrochoeris hydrochaeris), in M. Rechcigl (Ed). Handbock Series in Nutrition and Food, Sect G 1978; 1: 163-77. CRC Press, Cleveland.

7.- MARTÍNEZ F A, REARTE R, VILALTA B F, et al. Relevamiento coproparasitológico en mamíferos silvestres en cautiverio. Rev Therios 1997; 157-61.

8.- MELVIN D, BROOKE C. Métodos de laboratorio para diagnóstico de parásitos intestinales. Nueva Editorial Interamericana $1^{\text {ra }}$ Edición. 1971.

9.- MUNSON L, COOK R A. Monitoring, investigation and surveillance of diseases in captive wildlife. J Zoo and Wildl Med 1993; 24: 281-90.

10.- MONES A, MARTÍNEZ S. Estudios sobre la familia Hydrochoeridae (Rodentia) XVII. Parasitosis y patologías de Hydrochoeris hydrochaeris Brisson, 1762. Rev Fac Humanidades y Ciencia 1982; 1 : 297329.

11.- OJASTI J. El chigüire. Defensa de la naturaleza. Venezuela 1971; 3: 1-10.

12.- OJASTI J. Estudios Biológico del chigüire o capibara. Fondo Nac. Investigación Agropecuaria, Caracas 1973; $1-275$.

13.- QUINTANA R, PARERA A. El carpincho. Un recurso 
que espera. Anales 1994; (4/6): 18-22. Buenos Aires.

14.- RABINOVICH J, ALIOT J. Un análisis de opciones alternativas de manejo de poblaciones silvestres de chigüire (Hydrochoeris hydrochaeris). IVIC. 1978. pp. 63, Caracas.

15.- SCOTT M E. The impact of infection and disease on animal populations: Implications for conservacion biology. Conservation Biology 1988; 2: 40-56.

16.- SOSA BURGOS L. Comportamiento social del chigüire en relación con su manejo en cautiverio. Tesis. Univ. Central de Venezuela, Caracas. 1981. pp. 120.

17.- TRAVASSOS L, TEIXEIRA DE FLEITAS J F, KOHN A. Trematodeos do Brasil. Mem Inst Oswaldo Cruz
Fascículo Único 1969. pp. 1-880.

18.- WEBSTER R W Jr, ALLISON V F, UBELAKER J E, RIDDLE J M. Glycerine preparation of nematode material for scanning electron microscopy. Texas Rep Biol Med 1971; 29: 433-4.

19.- WEISS R W. Preparation of helminthes for scanning electron micrscopy. Proc. $31^{\text {st }}$ Electron microscopy Soc. Amer. (Ed. By C. J. Arceneaux). 1973. pp. 438-439. Claitor's Publishing Div., Baton rouge, La.

20.- YAMAGUTI S. Synopsis of digenetic trematodes of vertebrates. Keigaku Publishing Cp Tokyo. 1970. pp. $1-1074$.

\section{ATENCIÓN A LOS AUTORES}

PARA AGILIZAR LA EDICION DE PARASITOLOGIA LATINOAMERICANA, LOS AUTORES DEBERAN ENVIAR POR CORREO LOS ARTICULOS CIENTIFICOS GRABADOS EN UN DISKETTE DE 3 1/2 EN WORD 6.0 O SUPERIOR JUNTO CON EL MANUSCRITO DEL TRABAJO A PUBLICAR O ADJUNTARLO POR CORREO ELECTRONICO A halcaino@uchile.cl 